\title{
Synthesis of Pyrazolo[2,3-a]quinolines
}

\author{
Structure Elucidation and Reactions. An Unexpected Catalytic \\ Influence of Phenylhydrazine
}

\author{
CHRISTIAN L. PEDERSEN and OLE BUCHARDT
}

Chemical Laboratory II (General and Organic Chemistry), University of Copenhagen, The H. C. Orsted Institute, Universitetsparken 5, DK-2100 Copenhagen Ø, Denmark

\begin{abstract}
Treatment of 2,4,6-triarylpyrylium salts with excess phenylhydrazine leads, in a rather general reaction, to the formation of pyrazolo[2,3-a]quinolines. The structure of this new type of product is elucidated by spectroscopy and chemistry. It is shown that these new compounds have useful synthetic possibilities, in that they can be transformed either photochemically or by treatment with lithium aluminium hydride to 2,4-diarylquinolines, and by oxidation and hydrolysis to carbostyrils and $N$-aminocarbostyrils. The reaction pathways involved in these chemical transformations are discussed. It is inferred that the pyrazolo[2,3-a]quinolines are generated in a three step reaction from the pyrylium salts.
\end{abstract}

$\mathrm{T}$

he reaction between 2,4,6-triphenylpyrylium salts (Ia) and phenylhydrazine has been studied a number of times. ${ }^{1-5}$ The structure of the primary isolable product was recently established as IIa.$^{5}$ Compound IIa can isomerize in two ways, leading either to 1,3,5-triphenyl-3-phenacyl-2-pyrazoline (IIIa) * (by boiling in ethanol) ${ }^{1,2,5}$ or to the $N$-imide (IVa) (by boiling in acetic acid and treating with base). ${ }^{2,6}$ As described previously, ${ }^{6}$ further treatment of either IIa or IIIa with excess phenylhydrazine results in the generation of phenylhydrazones which are formulated as $\mathrm{Va}$ and $\mathrm{VIa}$, respectively, on the basis of the work of Balaban. ${ }^{5,7}$ However, we found that treatment of Ia with excess phenylhydrazine in boiling $96 \%$ ethanol led to the formation of a new compound to which we assign structure VIIa.

In order to get an impression of the general applicability of this novel reaction, it was tried on two other 2,4,6-triarylpyrylium salts, in each case successfully. We should like to emphasize, though, that no systematic attempts were undertaken to maximize yields.

\footnotetext{
* Compounds of type II and III were previously described as: $a$. Ring-chain tautomers; however, the tautomer II was believed to be a pyrane derivative, ${ }^{b} b$. Prototropic tautomers (hydrazone $\rightleftharpoons$ azo-compound). ${ }^{2}$
} 


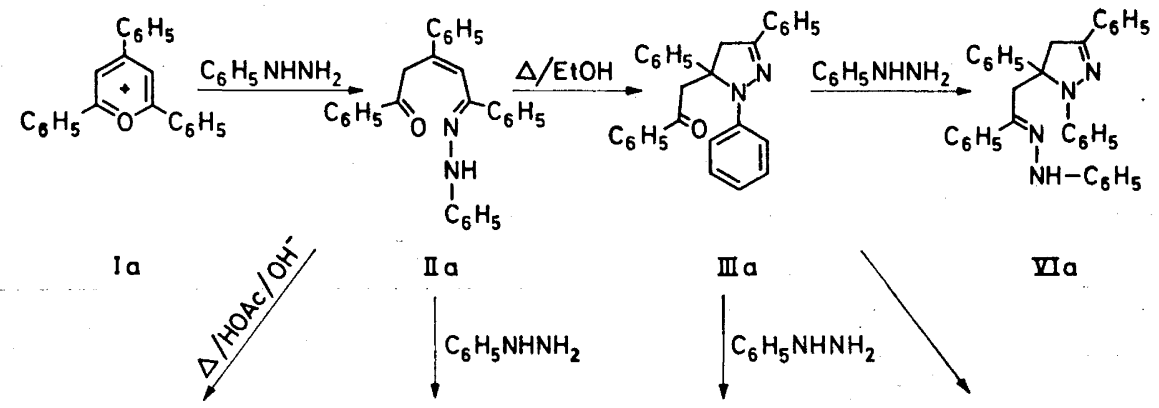

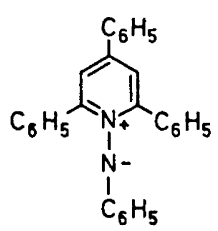

II $a$

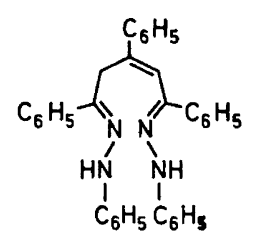

$\nabla a$

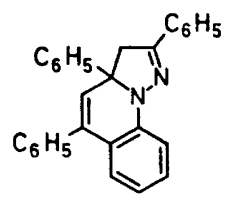

ZII a

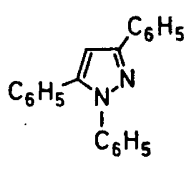

IIII a

Chart 1

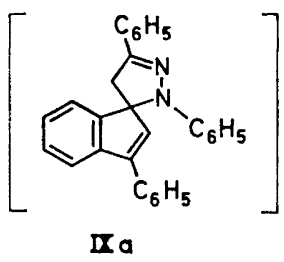

\section{STRUCTURE ELUCIDATION AND CHEMISTRY OF COMPOUND VIIa}

The assignment of a definite structure to compound VIIa is based on its spectroscopic properties and its chemical reactions. The IR and UV spectra (Table 1) do not permit any definite conclusions to be drawn about the structure, but are, however, in excellent agreement with our assignment. The NMR spectrum (Table 2) showed that compound VIIa contained 19 aromatic protons,

Table 1. Characteristic ultraviolet and infrared absorptions of compounds VIIa-c.

\begin{tabular}{|c|c|c|c|c|c|c|c|c|c|c|}
\hline \multirow{2}{*}{$\begin{array}{l}\text { Com- } \\
\text { pound }\end{array}$} & \multirow{2}{*}{\multicolumn{2}{|c|}{ IR $\left.\underset{\mathrm{cm}^{-1}}{(\text { in }} \mathrm{KBr}\right)$}} & \multicolumn{8}{|c|}{ UV (in $96 \%$ ethanol) } \\
\hline & & & $\lambda_{\max }$ & $\log e$ & $\lambda_{\max }$ & $\log \varepsilon$ & $\lambda_{\max }^{\max }$ & $\log \varepsilon$ & $\lambda_{\max }$ & $\log \varepsilon$ \\
\hline VIIa & 1600, & 1484 & 210 & 4.33 & 236 & 4.38 & $276(\mathrm{sh})$ & 3.87 & 370 & 4.18 \\
\hline VIIb & 1600, & 1480 & 209 & 4.54 & 240 & 4.55 & - & - & 380 & 4.34 \\
\hline VIIc & 1599, & 1481 & 207 & 4.47 & 232 & 4.41 & $275(\mathrm{sh})$ & 3.30 & 371 & 4.06 \\
\hline
\end{tabular}

Acta Chem. Scand. 24 (1970) No. 3 
Table 2. Nuclear magnetic resonance spectra of compounds VIIa $-\mathrm{c}^{a}$

\begin{tabular}{|l|c|c|c|c|c|c|}
\hline Compound & Vinyl proton & $\mathrm{H}_{\mathrm{A}}{ }^{b}$ & $\mathrm{H}_{\mathrm{B}}{ }^{b}$ & $J_{\mathrm{AB}}$ & Aromatic & Other \\
\hline VIIa & $3.45(1 \mathrm{H})$ & 6.14 & 6.26 & 17.4 & $2.1-3.3(19 \mathrm{H})$ & \\
VIIb & $3.44(\mathrm{l} H)$ & 6.24 & 6.36 & 17.4 & $2.2-3.3(17 \mathrm{H})$ & \\
VIIc & $3.50(\mathrm{H} H)$ & 6.27 & 6.40 & 17.6 & $2.1-3.3(18 \mathrm{H})$ & $7.80\left(\mathrm{CH}_{3}\right)(3 \mathrm{H})$ \\
\hline
\end{tabular}

a Spectra recorded at $100 \mathrm{MHz}$ with DMSO- $d_{6}$ as solvent and tetramethylsilane as internal reference. Chemical shifts are in $\tau$ values and coupling constants in $\mathrm{Hz}$. The position of the $\mathbf{A}$ or $\mathbf{B}$ part of the $A B$ quartet is calculated. Relative intensity is given in parenthesis.

$b$ Relative intensity of the $\mathrm{AB}$ part is 2 .

Table 3. Ultraviolet and infrared absorptions of compounds X, XI, XII, and XIII.

\begin{tabular}{|c|c|c|c|c|c|c|c|c|c|}
\hline \multirow{2}{*}{$\begin{array}{l}\text { Com- } \\
\text { pound }\end{array}$} & \multirow{2}{*}{ IR $\underset{\mathrm{cm}^{-1}}{\text { in } \mathrm{KBr})}$} & \multicolumn{8}{|c|}{ UV } \\
\hline & & $\frac{\lambda_{\max }}{\mathrm{m} \mu}$ & $\log \varepsilon$ & $\begin{array}{l}\lambda_{\max } \\
\mathrm{m} \mu\end{array}$ & $\log \varepsilon$ & $\begin{array}{l}\lambda_{\max } \\
\mathrm{m} \mu\end{array}$ & $\log \varepsilon$ & $\frac{\lambda_{\max }}{\mathrm{m} \mu}$ & $\log \varepsilon$ \\
\hline $\begin{array}{l}\mathrm{X}^{a} \\
\mathrm{XI}^{b}\end{array}$ & $\begin{array}{l}1606,1464 \\
1670(\mathrm{C}=\mathrm{O}) \\
1647(\mathrm{C}=\mathrm{O})\end{array}$ & $\begin{array}{l}212 \\
251\end{array}$ & $\begin{array}{l}4.15 \\
4.39\end{array}$ & $\begin{array}{l}245 \\
295 \mathrm{sh}\end{array}$ & $\begin{array}{l}4.08 \\
4.16\end{array}$ & $\begin{array}{l}275 \\
\text { 343sh }\end{array}$ & $\begin{array}{l}4.24 \\
3.71\end{array}$ & $\begin{array}{l}353 \\
378 s h\end{array}$ & $\begin{array}{l}3.60 \\
3.35\end{array}$ \\
\hline XII ${ }^{a}$ & $\begin{array}{l}3310(\mathrm{NH}) \\
3205(\mathrm{NH}) \\
1653(\mathrm{C}=\mathrm{O})\end{array}$ & 206 & 4.39 & 233 & 4.63 & 283 & 3.85 & 336 & 3.74 \\
\hline XIII $^{a}$ & & 212 & 3.98 & 234 & 4.12 & 279 & 3.59 & 332 & 3.48 \\
\hline
\end{tabular}

${ }^{a}$ UV Spectra recorded in $96 \%$ ethanol.

${ }^{b}$ UV Spectra recorded in chloroform.

Table 4. Nuclear magnetic resonance spectra of compounds X, XI and XII. ${ }^{a}$

\begin{tabular}{|c|c|c|c|}
\hline Compound & Aromatic & Vinylic & Amino \\
\hline X & $1.1-2.8$ & & \\
XI & $1.9-3.0(19 \mathrm{H})$ & $3.51(1 \mathrm{H})$ & \\
XII & $1.8-3.0(9 \mathrm{H})$ & $3.31(1 \mathrm{H})$ & $4.88(2 \mathrm{H})$ \\
\hline
\end{tabular}

${ }^{a}$ Spectra recorded at $60 \mathrm{MHz}$ in $\mathrm{CDCl}_{3}$ with tetramethylsilane as internal reference. Chemical shifts are in $\tau$ values. Relative intensity given in parenthesis.

i.e. a substitution reaction in one of the aromatic rings is strongly indicated. Furthermore, signals due to one vinylic proton and two methylene protons were observed. The former appeared as a singlet whereas the latter appeared as two doublets with a coupling constant of $17.4 \mathrm{~Hz}$, a value characteristic of geminal coupling. 
P Y R A Z L O [2,3-a] Q U I N O I I E S

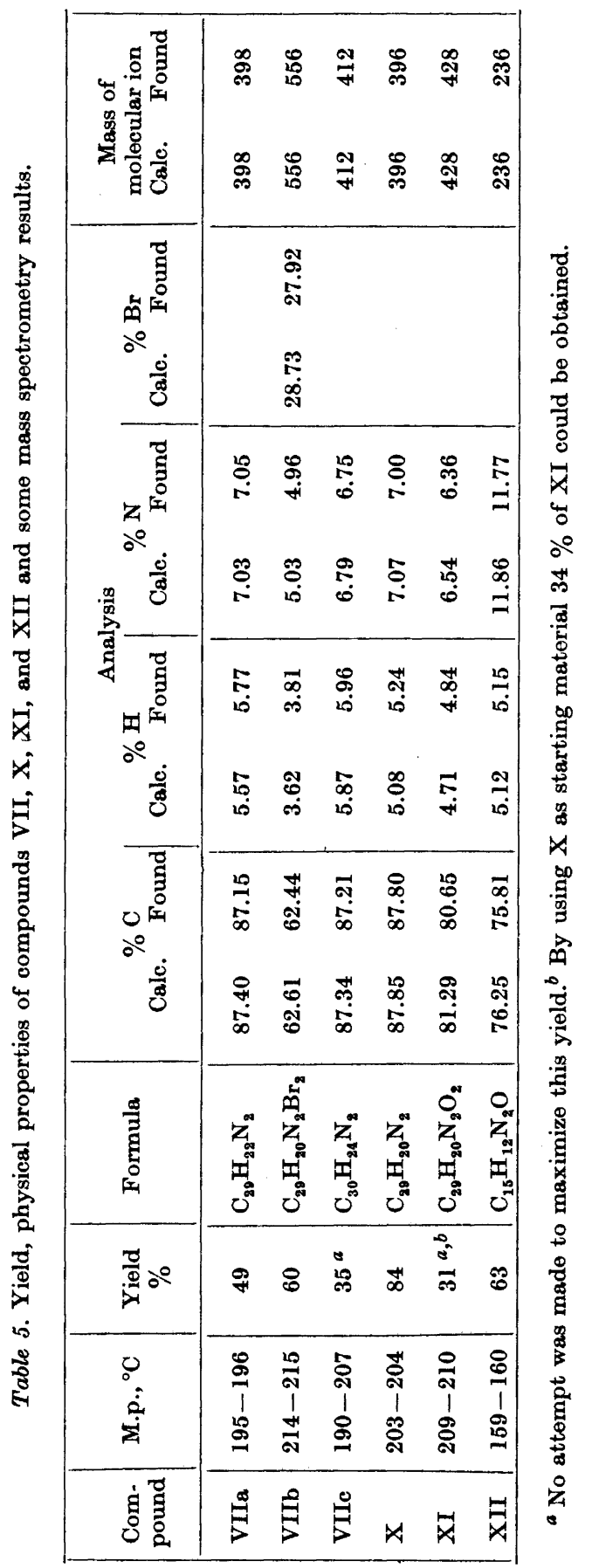

Acta Chem. Scand, 24 (1970) No. 3 
These spectroscopic properties were suggestive of two structures, i.e. formula VIIa and IXa. Structure VIIa was preferred on the basis of the following results:

a. Oxidation of VIIa $\left(\mathrm{C}_{29} \mathrm{H}_{22} \mathrm{~N}_{2}\right) *$ with iodine in dimethylsulfoxide resulted in the formation, in good yield, of a new compound, $\mathrm{X}\left(\mathrm{C}_{29} \mathrm{H}_{20} \mathrm{~N}_{2}\right)$. ${ }^{*}$ This compound appeared to be wholly aromatic on the basis of its spectroscopic properties (Tables 3-4). This was also confirmed by its chemical stability. For instance, it resisted attack by either concentrated acids or bases over prolonged periods. Further oxidation of compound $\mathrm{X}$ with chromium trioxide in acetic acid resulted in the formation, in moderate yield, of a compound $\mathrm{XI}\left(\mathrm{C}_{29} \mathrm{H}_{20} \mathrm{~N}_{2} \mathrm{O}_{2}\right)$.

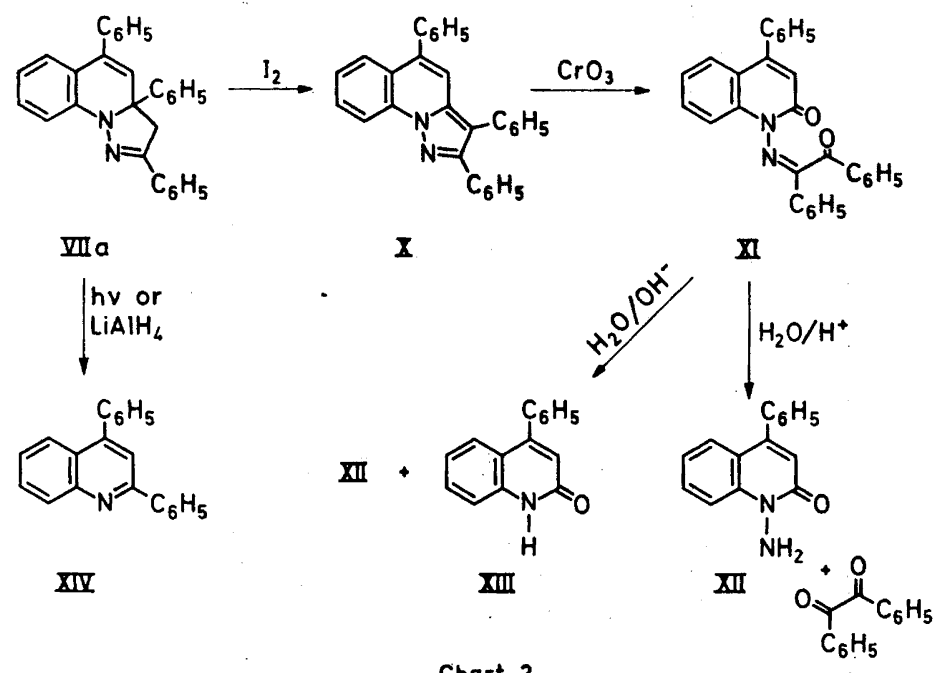

Chart 2

Compound XI contains two carbonyl functions (see its IR absorptions in Table 3), but its structure was, however, definitely assigned on the basis of its hydrolysis products. Hydrolysis under strongly acidic conditions gave benzil ** and a compound XII $\left(\mathrm{C}_{15} \mathrm{H}_{12} \mathrm{~N}_{2} \mathrm{O}\right)$. ${ }^{*}$ Compound XII is believed to be $N$-amino-4-phenylcarbostyril on the basis of its UV spectrum, which is very similar to that of 4-phenylcarbostyril (Table 3), and on the basis of its IR and NMR spectra (Tables 3-4). If the hydrolysis of compound XI was carried out under basic conditions 4-phenylcarbostyril (XIII) ** could be obtained.

$b$. Treatment of VIIa with lithium aluminium hydride resulted in its almost quantitative conversion to 2,4-diphenylquinoline (XIV).** Photolysis of VIIa also resulted in its transformation to XIV, although not in as high a yield as by its treatment with lithium aluminium hydride.

\footnotetext{
* Found by elemental analysis and confirmed by a mass spectrum (Table 5).

** Identified by comparison with an authentic sample; IR and mixed m.p.
} 
On the basis of these spectroscopic and chemical data we feel confident in our structural assignments. Compounds VIIb and $\mathrm{c}$ are identified on the basis of their similarity to compound VIIa (see Tables 1, 2, 5).

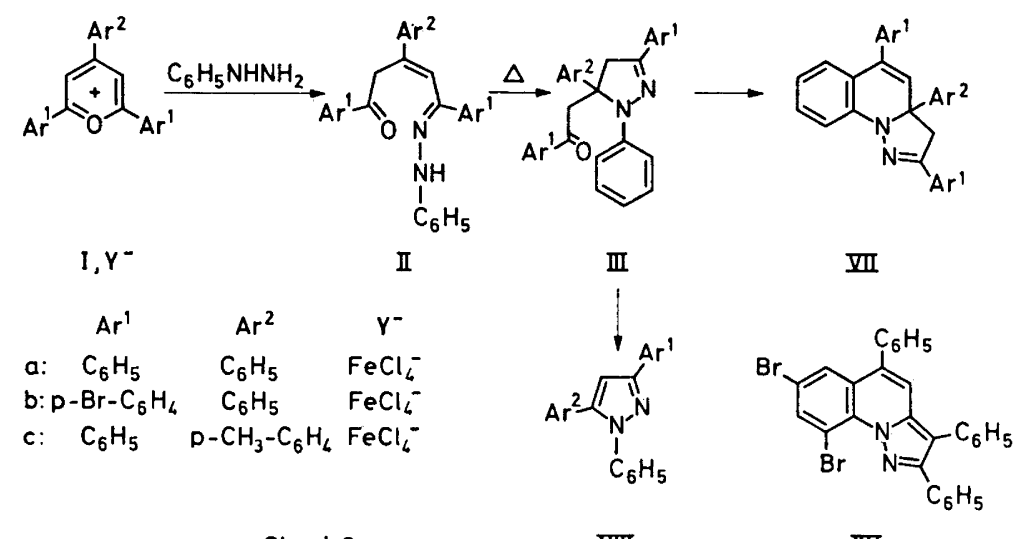

Chart 3

$$
\text { VIII }
$$

XI

Some further chemical experiments were undertaken with compound VIIa. Treatment with bromine in chloroform resulted in the formation of a violet compound which according to its elemental analysis has the molecular formula $\mathrm{C}_{29} \mathrm{H}_{21} \mathrm{~N}_{2} \mathrm{Br}_{5}$, 0.41 $\mathrm{CHCl}_{3}$. Boiling of this compound in chloroform for a short time gave a compound which may have the structure $X V$ (see experimental part). By treating VIIa with $N$-bromosuccinimide in tetrachloromethane a complicated reaction mixture was obtained which, by preparative layer chromatography (PLC), was separated into $\mathrm{XV}$, a compound with the molecular formula $\mathrm{C}_{29} \mathrm{H}_{19} \mathrm{~N}_{2} \mathrm{Br}$ and $\mathrm{X}$. No attempts were undertaken to assign a structure to the monobromo derivative.

\section{DISCUSSION OF REACTION PATHWAYS}

As mentioned in the introduction, treatment of IIa and IIIa with phenylhydrazine as previously described, ${ }^{6}$ resulted in the formation of the phenylhydrazones Va and VIa, respectively. This made it of obvious interest to examine whether $\mathrm{Va}$ or $\mathrm{VIa}$ could be intermediates in the formation of VIIa from the pyrylium salt Ia (see Chart 1). However, under conditions where good yields of VIIa were obtained from Ia and phenylhydrazine, no observable formation of VIIa took place from Va or from VIa. On the other hand, we could show that treatment of IIIa with phenylhydrazine under the same conditions led to the formation of VIIa in good yields (Charts 1 and 3). In this reaction, as well as in the direct treatment of the 2,4,6-triarylpyrylium salts (I) with phenylhydrazine, the persistent formation of compounds VIII diminished the preparative value of the method. Having established the role of phenylhydrazine as a catalyst in the manner described above, we tested some

Acta Chem. Scand. 24 (1970) No. 3 
other agents, e.g. hydrazine, hydroxylamine, and triethylamine, etc. None of these, however, showed a similar activity.

The 1,2-phenyl shift which takes place during the oxidation of VIIa to $\mathrm{X}$ is initiated presumably by removal of a hydride ion from the methylene group. The resulting secondary carbonium ion then rearranges, losing a proton (Chart 2).

Several attempts to regenerate compound XI from $N$-amino-4-phenylcarbostyril and benzil were unsuccessful.

\section{CONCLUDING REMARKS}

The novel reactions discussed in this paper lead to heterocyclic systems which are very difficult to obtain by other methods. Furthermore, they constitute a novel quinoline and carbostyril synthesis and lead to $N$-aminocarbostyril derivatives; a group of compounds which are apparently very tedious to prepare otherwise. Since 2,4,6-triarylpyrylium compounds are very easy to prepare, we can conclude that the synthetic possibilities of these novel reactions are quite good. We are presently investigating the reaction between 2,4,6-triarylpyrylium salts and nitrite ion in water and alcohols and expect to report these results shortly.

\section{EXPERIMENTAL}

Microanalyses were carried out in the microanalysis department of this laboratory by Mr. Preben Hansen and his staff.

Melting points (uncorrected) were determined on a Reichert melting point microscope or on a Büchi melting point apparatus.

Infrared spectra were recorded on a Perkin Elmer Model 337 grating infrared spectrophotometer. Ultraviolet spectra were recorded on a Perkin Elmer Model 137 UV spectrophotometer. Nuclear magnetic resonance spectra were recorded on a Varian A $60 \mathrm{~A}$ or HA 100 spectrometer. Mass spectra were obtained with an A. E. I. MS-9 instrument, using direct sample insertion into the ion source. The ionizing energy was maintained at $70 \mathrm{eV}$.

Preparative layer chromatography (PLC) was performed using $20 \times 100 \mathrm{~cm}$ plates with a $2.5 \mathrm{~mm}$ thick layer of silica gel (Merck $\mathbf{P F}_{254+3 c e}$ ). The plates were developed 2-3 times with benzene or with ethyl acetate. The fractions were isolated by continuous extraction with chloroform in a Soxhlet apparatus.

Pyrylium salts. These were prepared according to the method of Dilthey.

Reaction of pyrylium salts with phenylhydrazine. Compounds II, ${ }^{\mathbf{s}}$ III, ${ }^{\mathbf{s}}$ IV,,$^{\mathbf{s}} \mathrm{V}$, and VI ${ }^{\circ}$ were prepared according to the previously described methods. ${ }^{5,6}$ Compounds VII were all prepared according to the following procedure: 2,4,6-triphenylpyrylium tetrachloroferrate $(10.0 \mathrm{~g})$ was suspended in $96 \%$ ethanol $(200 \mathrm{ml})$ and phenylhydrazine $(4.26 \mathrm{~g})$ was added. This mixture was refluxed for $14 \mathrm{~h}$, cooled and the precipitated compound VIIa isolated by filtration $(3.86 \mathrm{~g}, 49 \%)$. Recrystallization from ethanol raised the m.p. to $195-196^{\circ} \mathrm{C}$. After evaporation of the solvent the residue from the above reaction was separated into 1,3,5-triphenylpyrazole (VIIIa) $(2.26 \mathrm{~g}, 39 \%$ ), identical with an authentic sample, and a minor amount of VIIa. Furthermore, some acetophenone was found.

Oxidation of VIIa with iodine. Compound VIIa $(2.00 \mathrm{~g})$ was dissolved in dimethyl sulfoxide $(80 \mathrm{ml})$ and methyl iodide $(20 \mathrm{ml})$ was added. The solution was refluxed for $14 \mathrm{~h}$ after which it was poured into an aqueous solution of sodium thiosulfate. By extraction with chloroform and evaporation of the solvent, $1.67 \mathrm{~g}(84 \%)$ of crude $\mathrm{X}$ was obtained. PLC, followed by recrystallization from ethanol-benzene, gave analytically pure material 
(Table 5). Furthermore, a minor amount of a crystalline non-identified compound was found.

Preparation of compound XI. a. Compound X (200 mg) in acetic acid (15 ml) and chromium trioxide $(200 \mathrm{mg}$ ) was stirred for $14 \mathrm{~h}$ at room temperature. The reaction mixture was diluted with water $(80 \mathrm{ml})$ and extracted with chloroform. After drying over anhydrous magnesium sulfate and evaporation of the solvent, the residue was worked up by PLC. This, after recrystallization from acetone or from ethyl acetate, permitted the isolation of $73 \mathrm{mg}(34 \%$ ) of compound XI (see Table 5). b. Compound VIIa $(2.52 \mathrm{~g})$ in acetic acid $(150 \mathrm{ml})$ and chromium trioxide $(2.50 \mathrm{~g})$ was stirred for two days at room temperature. The reaction mixture was diluted with water $(250 \mathrm{ml})$ and extracted with chloroform. After drying over anhydrous magnesium sulfate and evaporation of the solvent, trituration with acetone of the residue yielded $893 \mathrm{mg}$ of compound XI. A further amount of XI (392 $\mathrm{mg})$ was obtained by PLC of the residue from the above mother liquor (total yield, $31 \%$ ). Recrystallization from acetone or ethyl acetate gave analytically pure XI (Table 5).

Hydrolysis of XI under acid conditions. Compound XI $(880 \mathrm{mg})$ was dissolved in chloroform $(25 \mathrm{ml})$. To this solution was added concentrated hydrochloric acid $(5 \mathrm{ml})$ and the resulting two phase system was stirred vigorously for $1.5 \mathrm{~h}$. During this $\mathrm{N}$-amino4-phenylcarbostyril (XII) in the form of its hydrochloride separated and was removed by filtration $(350 \mathrm{mg}, 63 \%)$. It could be converted to the free base by treatment with sodium hydrogen carbonate. Recrystallization of the free base from methanol resulted in an analytically pure sample (Table 5). The chloroform phase was separated, dried over anhydrous magnesium sulfate and the solvent evaporated. The residue, after recrystallization from ethanol gave a yellow substance, m.p. $91-92^{\circ} \mathrm{C}$, which was identified as benzil.

Hydrolysis of XI under basic conditions. Compound XI $(260 \mathrm{mg})$ was dissolved in a mixture of ethanol $(25 \mathrm{ml})$ and $4 \mathrm{~N}$ sodium hydroxide $(5 \mathrm{ml})$. The solution was refluxed for $30 \mathrm{~min}$, the solvents removed in vacuo, and the residue separated by PLC into $N$ amino-4-phenylcarbostyril (XII) $(60 \mathrm{mg}, 42 \%)$ and 4-phenylcarbostyril (XIII) (31 mg, $23 \%$ ), identical with an authentic sample. ${ }^{10}$

Preparation of 2,4-diphenylquinoline (XIV) from VIIa.a. Compound VIIa $(0.50 \mathrm{~g})$ and lithium aluminium hydride $(1.02 \mathrm{~g})$ were suspended in dioxane $(50 \mathrm{ml})$. The suspension was refluxed for $1 \mathrm{~h}$. After addition of acetone and water and removal of the pre. cipitated inorganic materials by filtration, evaporation of the solvent gave an almost quantitative amount of 2,4-diphenylquinoline (identical with an authentic sample ${ }^{11}$ ). $b$. Compound VIIa $(2.00 \mathrm{~g})$ was dissolved in benzene $(200 \mathrm{ml})$. This solution was irradiated, using the RUL 3500 lamps of a Rayonet reactor (type RPR-208), for $29 \mathrm{~h}$. After this, the solvent was removed and the residue separated by PLC. This gave unreacted starting material (74 mg), some by-products in minor amounts, and 2,4-diphenylquinoline (874 $\mathrm{mg}, 64 \%)$.

Preparation of compound VIIa from 1,3,5-triphenyl-5-phenacyl-2-pyrazoline (IIIa) and attempts to prepare compound VIIa from the phenylhydrazones Va and VIa. 1,3,5Triphenyl-5-phenacyl-2-pyrazoline $(650 \mathrm{mg})$ and phenylhydrazine $(169 \mathrm{mg})$ were added to ethanol $(16 \mathrm{ml})$ and the reaction mixture refluxed for $14 \mathrm{~h}$. After this the solvent was removed in vacuo and the residue separated by PLC into VIIa (275 mg, 44 \%) and 1,3,5-triphenylpyrazole (99 mg, $21 \%$ ). When the hydrazones Va and VIa were boiled in ethanol no trace of VIIa was observed.

Reaction between compound VIIa and bromine. Compound VIIa $(2.0 \mathrm{~g})$ was dissolved in chloroform $(50 \mathrm{ml})$, and bromine $(2.4 \mathrm{~g})$ was added. After $c a .1 \mathrm{~h}$ at $-40^{\circ} \mathrm{C}$ the precipitated violet crystals were filtered off $(4.03 \mathrm{~g})$. (Found: $\mathrm{C} 41.60 ; \mathrm{H} 2.55 ; \mathrm{N} 3.29 ; \mathrm{Br}$ 47.35; Cl 5.18. Calc. for $\mathrm{C}_{28} \mathrm{H}_{21} \mathrm{~N}_{2} \mathrm{Br}_{5}, 0.41 \mathrm{CHCl}_{3}$ : C 41.76; $\mathrm{H} \mathrm{2.55;} \mathrm{N} \mathrm{3.31;} \mathrm{Br} 47.23 ; \mathrm{Cl}$ 5.15). This compound is very unstable and decomposes readily; e.g. by boiling for $20 \mathrm{~min}$ in chloroform. This results in the formation of a new compound (XI) which after recrystallization from methanol melts at $236-238^{\circ} \mathrm{C}$. (Found: $\mathrm{C} \mathrm{62.82;} \mathrm{H} 3.40 ; \mathrm{N} \mathrm{4.99;} \mathrm{Br} 28.00$ Calc. for $\mathrm{C}_{29} \mathrm{H}_{18} \mathrm{~N}_{2} \mathrm{Br}_{2}$ : C 62.84; $\mathrm{H} 3.27 ; \mathrm{N} 5.05 ; \mathrm{Br} 28.83$ ). IR: $\mathrm{No} \mathrm{OH}, \mathrm{NH}$ or $\mathrm{CO}$, but obvious absorptions due to aromatic rings. UV: $\left(\mathrm{CHCl}_{3}\right) \dot{\lambda}_{\max } 358 \mathrm{~m} \mu(\log \varepsilon=3.95)$, $286 \mathrm{~m} \mu(\log \varepsilon=4.63)$. NMR: Very similar to that of X (it should be noted that the structure proposed above is purely speculative).

Reaction between VIIa and N-bromosuccinimide. Compound VIIa $(2.00 \mathrm{~g})$ and $N$. bromosuccinimide $(1.80 \mathrm{~g})$ were dissolved in tetrachloromethane $(50 \mathrm{ml})$ and refluxed for $2 \mathrm{~h}$. After this the solvent was removed and the residue separated by PLC into: 1 .

Acta Chem. Scand. 24 (1970) No. 3 
Unidentified crystalline material (51 mg); 2. A compound which was shown to be identical with the dibromo derivative described above $(635 \mathrm{mg}) ; 3$. A crystalline monobromo compound, m.p. $215-224^{\circ} \mathrm{C}$. (Found: C 73.15; $\mathrm{H} \mathrm{4.19;} \mathrm{N}$ 5.62; $\mathrm{Br}$ 17.03. Calc. for $\mathrm{C}_{20} \mathrm{H}_{10} \mathrm{~N}_{2} \mathrm{Br}$ : C 73.27; $\left.\mathrm{H} \mathrm{4.03;} \mathrm{N} \mathrm{5.89;} \mathrm{Br} 16.81,899 \mathrm{mg}\right)$. 4. Compound X (650 mg).

\section{REFERENCES}

1. Schneider, W. and Seebach, F. Ber. 54 (1921) 2285.

2. Schneider, W. Ann. 438 (1924) 115.

3. Lombard, R. and Kress, A. Bull. Soc. Chim. France 19601528.

4. Balaban, A. T., Frangopol, P. T., Matescu, G. and Nenitzescu, C. D. Bull. Soc. Chim. France 1962298.

5. Balaban, A. T. Tetrahedron 24 (1968) 5059.

6. Schneider, W. and Müller, W. Ann. 438 (1924) 147.

7. Balaban, A. T. Tetrahedron. To be published.

8. Dilthey, W. J. prakt. Chem. 94 (1916) 53.

9. Knorr, L. and Laubmann, H. Ber. 21 (1888) 1205.

10. Stephenson, E. F. M. J. Chem. Sac. 19562557.

11. Beyer, C. Ber. 20 (1887) 1767.

Received September 2, 1969. 